Revista Pax Domini é licenciada sob uma Licença Creative Commons.

\title{
DINÂMICAS RELIGIOSAS CONTEMPORÂNEAS COMO DESAFIO AO LABOR TEOLÓGICO EVANGÉLICO
}

Victor Breno Farias Barrozo ${ }^{1}$

\begin{abstract}
RESUMO
O labor teológico evangélico realiza-se dentro de um contexto mais amplo da tradução e significação da fé ante as transformações socioculturais de um determinado tempo histórico. Um dos principais panos de fundo a partir do qual se constroem os discursos teológicos é justamente o cenário religioso. Num quadro marcado pela emergência da modernidade religiosa, novas dinâmicas estruturam e influenciam o protestantismo evangélico brasileiro como a secularização, individualismo, pluralismo, mercado religioso, globalização e hibridismos. Apresentaremos no presente texto um mosaico das principais tendências que se colocam ao senso religioso contemporâneo como desafios à reflexão teológica evangélica.
\end{abstract}

Palavras-Chave: Labor teológico, Modernidade religiosa, Teologia evangélica, Dinâmicas sociorreligiosas.

\begin{abstract}
Evangelical theological labor occurs within the wider context of the translation and signification of faith in the face of the sociocultural transformations that occur in a given historical period. One of the main backgrounds from which theological discourse can be constructed is the religious situation. In a situation such as our own, marked by the emergence of religious modernity, new dynamics structure and influence brazilian evangelical protestantism, such as secularization, individualism, pluralism, the religious market, globalization and hybridization. In this text we shall present a mosaic of the main tendencies that present themselves to contemporary religious sensibility as challenges to evangelical theological reflection.
\end{abstract}

Keywords: Theological labor, Religious Modernity, Evangelical Theology, Socio-religious Dynamics

${ }^{1}$ Doutorando pelo Programa de Pós-Graduação em Ciências das Religiões na UFPB. Mestre e especialista em Ciências da Religião pela PUC Minas. Pós-graduado em Sociologia pela UGF. Graduado em Ciências Teológicas pela FBN. Email: victorbrenofb@gmail.com

Revista Pax Domini | Faculdade Boas Novas | vol. 1 | p. 102 - 117 | jul./dez. 2015 


\section{INTRODUÇÃO}

O saber teológico é uma expressão hermenêutica da fé que, de maneira crítica, busca pensar os sentidos da espiritualidade cristã na vida cotidiana dos indivíduos em comunidade e sua presença dentro do mundo no qual fazem parte. Entretanto, a teologia, como qualquer outra forma de conhecimento humanamente produzido, é parcialmente condicionado por um conjunto de elementos históricos e culturais mais amplos. Estes por sua vez, expressam o "espírito do tempo" de uma determinada realidade social, sobre a maneira como se autocompreendem, organizam e estruturam a vida em sociedade. Desta forma, o pensamento teológico é uma forma de compreensão tanto situada e influenciada por tais elementos socioculturais, quanto, elaborado a partir e em função de tais realidades.

A teologia, e em nosso caso, a teologia evangélica ${ }^{2}$, deve se colocar ao trabalho de depurar as malhas da tessitura social dentro do qual está envolvida para ser de fato ser um conhecimento da/para fé, pertinente e válido. Dentre os elementos imprescindíveis a tal atividade, seja a qualidade do discernimento que, funciona como um filtro de lucidez a respeito da elucidação das complexas variantes que compõem a tradução da experiência evangélica (do evangelho) a um determinado contexto e sociedade. Assim sendo, o fazer teológico evangélico que se queira relevante e contextualizado precisa necessariamente compreender estas mesmas articulações, problematizando a respeito das interpelações que produz sobre o cristianismo.

Das realidades socioculturais que mais diretamente afetam e condicionam a teologia evangélica, está o quadro do senso religioso contemporâneo. Este expressa às tendências em curso no cenário brasileiro que dão a lógica de fundo daquilo que poderíamos chamar de engenharia religiosa na atualidade. Como resultado da modernidade, o campo das religiões passa por significativas metamorfoses produzindo novas formas e expressões religiosas. Como diagnostica a socióloga francesa Danièle Hervieu-Léger (2008), nas sociedades modernas, a religião está em “movimento", fazendo emergir o que ela denomina de modernidade religiosa. Por modernidade religiosa, compreendemos as

\footnotetext{
${ }^{2}$ Por teologia evangélica, nos referimos à reflexão e prática da fé cristã no protestantismo evangélico brasileiro. Falar sobre teologia evangélica é por demais problemático e, não poucas vezes, controverso. Há de se perguntar em que medida existe uma teologia evangélica e como ela se expressa de maneira objetiva. A rigor, não existe uma teologia evangélica, mas sim, várias teologias evangélicas. Também, que não há uniformidade no modo como essas teologias se fazem e obtém seu espaço por entre as comunidades evangélicas no país. Para todos os efeitos, o protestantismo evangélico expressa certa teologia - por vezes de modo implícito, ou propositivamente, como crenças que possui a respeito do cristianismo. Nossa intenção no presente texto não é discutir as possibilidades ou não de concebermos uma teologia evangélica, mas, por necessidade de uma categoria tipológica, nos utilizaremos genericamente dessa noção.
}

Revista Pax Domini | Faculdade Boas Novas | vol. 1 | p. 102 - 117 | jul./dez. 2015 
dinâmicas e condição contemporâneas que caracterizam o cenário das religiões na atualidade.

Tal realidade afeta não apenas o comportamento das tradições e instituições religiosas em particular, mas, também, o background do da reflexão teológica como um todo. Dessa forma, queremos pensar no presente texto quais são algumas destas novas dinâmicas próprias da modernidade religiosa que interpelam-se como desafio ao labor teológico evangélico. Nos deteremos - pelo espaço de tempo disponível e pelos objetivos propostos - em apresentar os elementos gerais destas dinâmicas em vista fornecer um mosaico para a problematização posterior do modo específico que cada uma provoca sobre o escopo teológico.

\section{RUMO À UMA SOCIEDADE SECULARIZADA}

Etimologicamente, o termo refere-se à desapropriação dos bens eclesiais da Igreja Católica Romana para as mãos dos poderes seculares (política/economia) a partir da Revolução Francesa no século XVI. Como noção sociológica, começa a ser utilizada de maneira sistemática em meados dos anos 1960, no contexto anglo-saxão, para pensar as complexas relações entre religião e modernidade. As diferentes acepções na qual o termo é utilizado, contemporaneamente, o torna um conceito polissêmico. Entretanto, de uma maneira em geral, tal noção procura compreender o enfraquecimento em graus diferentes em contextos distintos - do lugar que a religião ocupa na vida e organização cultural das sociedades modernas.

Formalmente, a teoria da secularização foi preconizada pelos clássicos do pensamento sociológico - Marx falava de emancipação, enquanto Durkheim sublinhava o termo secularização e, Weber diria do desencantamento do mundo. Para ambos, em graus e acepções distintas, a evicção da modernidade iminentemente conduziria as sociedades ocidentais ao fim da religião. Entretanto, desde a década de 70, com o surgimento de novas correntes religiosas, no fluxo dos movimentos contraculturais, começou-se a conceber a ideia de secularização numa compreensão mais alargada.

Destacamos dois aspectos perspectiva ampliada da secularização. Primeiro, para o sociólogo americano Peter Berger, a secularização é o "processo pelo qual setores da sociedade e da cultura são subtraídos à dominação das instituições e símbolos religioso" (1985, p.119) e ainda que seria caracterizada pelo "fim dos monopólios das tradições religiosas" (1985, p.146). Ou seja, secularização é o fenômeno pelo qual a religião vai perdendo sua plausibilidade e força de coesão social, tornando-se conteúdo exclusivo da experiência e prática privada. Progressivamente, o religioso tem retraída sua

Revista Pax Domini | Faculdade Boas Novas | vol. 1 | p. 102 - 117 | jul./dez. 2015 
capacidade normativa e aglutinadora de sentido ao conjunto da sociedade sendo execrada dos espaços que anteriormente possuía influência.

Essa secularização operaria em graus distintos na sociedade, tendo seu efeito pode variado de cultura para cultura, de país para país e de sociedade para sociedade. Entretanto, de uma forma em geral existem pelo menos três níveis de sua atuação, saber: Institucional, quando as instituições sociais e políticas (como escolas, partidos, sindicados) deixam de usar a religião como referência para regular as estruturas formais de organização institucional da vida em sociedade; Cognitivo, quando a religião deixa de ser um pressuposto a partir do qual se pensa o mundo, inferindo disso toda uma compreensão da realidade que prescinde de Deus; Comportamental, quando as condutas práticas dos indivíduos em sociedade não refletem ou não mais se baseiam em um ética religiosa, vivendo-se assim uma liberalidade moral dos valores e costumes.

Em segundo lugar, a secularização não apenas ela reduz a capacidade institucional das tradições religiosas de determinar e regular seus símbolos e práticas sobre a coletividade dos grupos sociais, mas possibilita o aparecimento de novas expressões religiosas. Ela é um movimento intenso de reorientação da dinâmica religiosa no interior da sociedade, que não aponta para o fim da experiência religiosa, mas sim, para uma nova forma de organizar-se. Para a francesa Danièle Hervieu-Léger (2008, p. 37), o processo de secularização:

\footnotetext{
Combina, de maneira complexa, a perda da influência dos grandes sistemas religiosos sobre uma sociedade que reivindica sua plena capacidade de orientar ela mesma seu destino, e a recomposição, sob uma forma nova, das representações religiosas que permitiram a esta sociedade pensar a si mesma como autônoma.
}

O senso religioso contemporâneo inaugura novas formas e expressões religiosas como produtos de uma modernidade secular. A recomposição da religião nas sociedades modernas implica o aparecimento de novos movimentos religiosos e dinâmicas que articulam o campo das religiões da atualidade. Desse modo, ao contrário das prospectivas clássicas da secularização, esta não aponta para a extinção da religião, mas, para o fim do domínio normativo das instituições religiosas sobre a sociedade e o ressurgimento de produções religiosas afeitas à modernidade.

Para os sociólogos Olivier Bobineau e Sébastien Tank-Storper (2011), a secularização não é um processo unilateral e nem compõem-se apenas de aspectos homogêneos. Esta integraria pelo menos

Revista Pax Domini | Faculdade Boas Novas | vol. 1 | p. 102 - 117 | jul./dez. 2015 
cinco dimensões constituintes da secularização enquanto fenômeno da cultura moderna ocidental. Primeiro, a secularização como processo de diferenciação institucional: significa dizer que a religião perde seu poder social de reger as instituições sociais, gerando um processo de autonomização (as instituições sociais tornam-se independentes umas das outras) e especialização (cada instituição social passa a cuidar do que é próprio de sua competência).

Em segundo lugar, a secularização como processo de pluralização: com a diferenciação institucional, a religião também deixa de ser homogênea (existir uma religião acima das outras, como a Igreja Católica na Idade Média) e passa-se a uma realidade de mercado religioso onde as igrejas se multiplicam entre várias denominações e se colocam num cenário de disputa e concorrência dos clientes-fieis pelo "produto-religioso". Terceiro, a secularização como processo de privatização e de individualização: cada vez mais a religião deixa de ser um assunto político na vida pública das sociedades e passa a se tornar uma questão privada dos indivíduos. Nessa visão, religião é algo a ser vivido individualmente na dimensão interior e não no espaço público.

Quarto, a secularização como processo de racionalização: certos domínios da vida que eram anteriormente regidos pelo imaginário religioso agora são guiadas pela razão científica e pela técnica instrumental. Cada vez mais o mundo se explica e se organiza pela razão e não pela religião. E por fim, a secularização como processo de mundanização: significa, por um lado, que a sociedade deixe de se interessar pelo mundo sobrenatural ou espiritual para se interessar pelas coisas deste mundo e, por outro lado, algumas igrejas que reorientam seu discurso de salvação não como a redenção da alma no pós-morte no céu, mas, a realização terrena dos sonhos de sucesso e satisfação holística.

Tais realidades apontam para o fato de que caminhamos rumo a sociedades cada vez mais secularizadas, onde as tradições religiosas deixam de conferir plausibilidade e coesão ao conjunto da sociedade, ao mesmo tempo que possibilita o surgimento de novas expressões religiosas caracterizadas pela modernidade. Essa mesma secularização, provoca a diferenciação institucional dos grupos sociais, na medida em que pluraliza o campo religioso, desencadeando uma tendência à privatização das crenças. Desde quadro, une-se ainda a racionalização da oferta religiosa, bem como também a mundanização da sua proposta à sociedade moderno-secular.

\section{INDIVIDUALIZAÇÃO DO RELIGIOSO NA MODERNIDADE}

Por certo, um dos traços mais distintivos e centrais dentre as dinâmicas contemporâneas é o

Revista Pax Domini | Faculdade Boas Novas | vol. 1 | p. 102 - 117 | jul./dez. 2015 
individualismo religioso ${ }^{3}$. O filósofo francês Frédéric Lenoir (2003), afirma que este processo de individualização seria comparado a uma "revolução copernicana" da consciência religiosa na modernidade. Tal tendência remonta a evicção do projeto humanista de autonomização do sujeito mediante a razão, posta em curso pelo Iluminismo. Neste, desenrola-se a crítica e emancipação da tradição religiosa de sobre a tutela normativa nas sociedades ocidentais, sobrepondo o indivíduo como centro e alvo da

Consolidada na modernidade, a individualização do religioso põem-se como uma tendência que atravessa o conjunto das religiões em torno da centralidade da experiência dos indivíduos na composição de seu universo de crenças e nas formas como constrói ou não sua sociabilidade religiosa. Esta marca a ascensão da "religião do indivíduo", onde os sujeitos tornam-se autorresponsáveis em suas trajetórias de busca espiritual, sendo sua própria realização o critério de autenticidade.

O Individualismo religioso moderno representa algumas questões bastante específicas: aponta tanto a desinstitucionalização religiosa (o enfraquecimento da autoridade e regulação institucional sobre os fiéis) quanto à desregulação da crença (o fraquejamento na normatividade da tradição na crença comunitária) e, em segundo lugar, pela evicção da religião “à la carte” onde a ação do sujeito de compor sua própria religião que, desamarrado da regulação da tradição, elabora sua crença e pertença a partir dos gostos e conveniências pessoais como afirmação de sua livre subjetividade.

“A religião que se professa hoje já não é aquela na qual se nasce, mas a que se escolhe", afirmou o sociólogo brasileiro Reginaldo Prandi (1990, p.51). Não mais uma determinada tradição que lega seu programa as futuras gerações, mas sim, elas passam a operar desde o imperativo da escolha pessoal. Os indivíduos passam a ter autonomia na constituição do seus próprios sistemas religiosos.

Essa crise implica também enfraquecimento do vínculo formal e baixo grau de comprometimento, tendendo ao desenvolvimento de uma relação de cunho mercantilista e pragmática. Até mesmos os métodos tradicionais de pesquisa sobre a filiação religiosa são desafiados a rever suas possibilidade e alcanças diante desde dado, como comentou Pierre Sanchis (2012, p.7) em recente entrevista:

Um dos grandes problemas religiosos do próximo século será o da relação do indivíduo com a instituição que lhe propicia uma identidade religiosa. Dizer-se

\footnotetext{
${ }^{3}$ Mesmo reconhecendo a distinção entre os conceitos de individualismo e individualização, manteremos o uso sinônimo de ambos, sem discriminação.
}

Revista Pax Domini | Faculdade Boas Novas | vol. 1 | p. 102 - 117 | jul./dez. 2015 
católico ou umbandista, até proclamar-se evangélico, não será mais unívoco. No caso de uma identidade tradicional, a situação está clara: continua-se aderindo a uma identidade, mas escolhe-se o conteúdo desta adesão. E mesmo no caso de uma conversão, na medida em que o tempo vai passando, a iniciativa individual na bricolagem de uma cosmovisão de fé e de um mapa de vida tende a se alargar. Nesse sentido, as pesquisas deverão afinar as suas perspectivas.

Religião se tornou opção de foro íntimo. Na modernidade religiosa compete tão somente ao indivíduo, em sua liberdade e autonomia, afirmar-se religioso ou não e a seu jeito. Por essa razão, as identidade religiosas hoje não são fruto do recebimento de uma herança familiar ou de uma identidade institucional, mas produto de um complexo circuito de composições e recomposições. É a emergência de novos personagens religiosos que passam a compor o mosaico complexo do religioso na atualidade.

A modernidade religiosa constitui-se como um momento da afirmação radical da escolha pessoal acima de qualquer outro elemento ou critério que venha a se colocar na constituição das identidades religiosas. Sendo assim, não apenas sua identidade passa a ser resultado provisório de trajetórias complexas, mas sua sociabilização comunitária tende fortemente a ser guiada pelo critério do individualismo.

O senso religioso contemporâneo não é caracterizado pela indiferença em relação à crença, mas sim, pela perda progressiva da regulamentação institucional dessa crença pelas Igrejas. O panorama religioso atual é marcado por essa disseminação acentuada da crença desprovida do ajustamento dos grandes sistemas religiosos. As evidências desta perda da regulamentação institucional do crer se manifestam em dois aspectos: na ruptura entre crença e prática; e na construção livre dos sistemas de fé pelos indivíduos, sem que haja necessariamente uma referência direta às crenças convencionadas pela instituição.

\section{O RELIGIOSO ENTRE O PLURALISMO E AS MALHAS DA LÓGICA DE MERCADO}

Além de reforçar e reinterar a dissolução diferida pela secularização sobre a religião, Berger também nos aponta para outro ponto importante. Com a derrocada da hegemonia religiosa entramos numa situação de pluralismo religioso. Não apenas uma organização religiosa conferiria sentido e significado para o mundo, mas agora, a possibilidade de múltiplas expressões religiosas.

A secularização fragmenta o campo religioso gerando uma realidade plural e multifacetada.

Revista Pax Domini | Faculdade Boas Novas | vol. 1 | p. 102 - 117 | jul./dez. 2015 
Existe nesse momento a possibilidade da livre vivência religiosa, ou até mesmo de abster-se dela. Emergem diferentes grupos religiosos com propostas e visões de mundo que se diferenciam entre si e passam a conviver num mesmo ambiente. Esta nova situação de pluralismo, de variadas possibilidades, passa a organiza-se a partir da lógica do mercado. Seguindo o que convencionalmente passou a ser chamado de paradigma do mercado religioso, Berger (1985, p. 149) afirma que:

A situação pluralista é, acima de tudo, uma situação de mercado. Nela, as instituições religiosas tornam-se agências de mercado e as tradições religiosas tornam-se bens de consumo. E, de qualquer forma, grande parte da atividade religiosa nessa situação vem a ser dominada pela lógica da economia de mercado.

A pluralização significa paralelamente o movimento de auto-organização das religiões sob a referência do mercado. Os elementos religiosos passam a ser objeto de consumo e apropriação individualizado do bem religioso. A partir de agora, o ethos de consumo será a lógica organizadora e dinamizadora do cenário religioso. Nesta nova realidade, as organizações religiosas têm de repensarem a si mesmas no intuito de poderem oferecer adequadamente seus serviços religiosos. Passam por um processo de racionalização, burocratizam-se e começam a se comportar de modo que possam produzir bens simbólicos que atendam a demanda do campo.

Temos então, descortinando diante de nós o fim de uma época religiosa, marcada pela centralização monolítica do poder e influencia religiosa, e o surgimento de um campo reordenado, plural, autônomo e que se estrutura a partir dos princípios de mercado. O professor Guerra (2003, p.1 2) já reiterava esse ponto quando nos diz que:

Nos contextos de pluralismo acentuado em que vivemos, passou o tempo em que as instituições religiosas podiam propor a sociedade um conjunto de exigências relativas à fé e aos comportamentos esperando uma aceitação social imediata. Nas sociedades contemporâneas, em que os indivíduos são crescentemente orientados para decidir livremente a respeito de que modelo de religiosidade vão adotar (quando escolhem um), o que as organizações religiosas oferecem tem que ser atrativo para os potenciais consumidores. [...] Essa dependência das instituições religiosas em relação à vontade dos consumidores parece variar de maneira diretamente proporcional ao nível de competição em um dado mercado religioso e também se relaciona com as mudanças no papel social da religião na

Revista Pax Domini | Faculdade Boas Novas | vol. 1 | p. 102 - 117 | jul./dez. 2015 
vida dos indivíduos, que têm produzido, entre outras coisas, uma tendência que aponta para um consumo fragmentário de religiosidade.

A secularização desestabiliza o monopólio religioso gerando um cenário plural e múltiplo de expressões religiosas. Nesta condição, de fragmentação do campo as religiões são postas num ambiente de mercado religioso, em que tem de utilizarem-se das lógicas de mercado e passam a viver em conflitos em relação aos bens simbólicos que oferecem. Sobre isso, o professor Portella (2006,p.46) diz que:

\begin{abstract}
A secularização, assim, revela o pluralismo religioso, e vice-versa, onde se rompem monopólios religioso de um único cosmos sagrado e se implanta o regime de concorrência entre os diversos agentes religiosos. [...] Dessa forma, cada religião/instituição deve-se lançar no “mercado religioso' como uma entre outras, usando as operações da economia de mercado, se adaptando as demandas e, assim, tendo mesmo que modificar, no limite, certos traços seus até então intocados. Sem querer exagerar, poderíamos dizer que, se antes, a religião moldava o indivíduo e seu mundo, hoje a tendência se inverte.
\end{abstract}

O campo religioso plural é resultado de sua secularização. As múltiplas expressões religiosas demonstram o encerramento de um período de hegemonia institucional e sua fragmentação. É nesse ambiente de múltiplas ofertas religiosas que as instituições se vêm diante de um grande desafio, de terem que conseguir adeptos no meio de tantas opções. Assim, as religiões são levadas a disputar seus fiéis-clientes assim como acontece com as instituições de mercado secular. Santana (2005, p.62-64) comenta que:

Para conseguir a adesão dos fiéis-clientes, a religião tem que agora usar da lógica da economia de mercado, pois o pluralismo religioso é uma situação de mercado. As tradição religiosas podem ou não ser assumidas como comodidades de consumo. Além disso, as tradições religiosas têm que disputar a "definição da realidade com rivas socialmente poderosos e legalmente tolerados [...] No pluralismo as estruturas de plausibilidade são multiplicadas, relativizadas e entram em concorrência. Os conteúdos religiosos passam a ser privados, individuais e passam a se referir à existência individual, a história de vida. A pluralidade faz com que os grupos religiosos busquem cada qual manter seu

Revista Pax Domini | Faculdade Boas Novas | vol. 1 | p. 102 - 117 | jul./dez. 2015 
fragmento frente aos outros fragmentos do mundo. Assim, as possibilidades de legitimações são muito variadas sem serem seguras. O indivíduo escolhe a legitimação, se certifica dela e a legitima com dados existenciais para si mesmo.

Nesta condição, as organizações religiosas são relativizadas e entram em concorrência. A escolha religiosa passa a ser pessoal e as experiências espirituais passam se tornar privados. Agora cada religião quer manter seu cosmos diante de outros cosmos, afirmando sua legitimidade. Neste contexto, as estruturas de plausibilidade religiosa tendem a disputar acirradamente seus fiéis. No caso brasileiro, as transformações de modernização do país afetaram o campo religioso, trazendo a secularização para a cena.

\section{TENSÕES E CONFLITOS DA CONCORRÊNCIA RELIGIOSA}

A partir deste momento, de pluralização decorrente da secularização do campo brasileiro, as instituições religiosas entram num mercado religioso e tem de disputar a clientela de fiéis. Passam então a investirem em propagandas de marketing, arraigam-se de elementos publicitários para legitimarem seu discurso e prática. Todavia, como veremos agora frente, essa concorrência é marcada por conflitos e confrontos que acirram a convivência de tradições diferentes promovendo um clima de digladiação, utilizando-se principalmente da mídia.

Entre as dinâmicas que ordenam a realidade do campo religioso brasileiro, a competição entre as instituições ocupa um lugar central dos eventos neste ambiente A concorrência religiosa não é algo nova. Todavia, a intensidade das disputas por legitimação, manutenção e expansão das estruturas eclesiásticas no Brasil tem conferido intensos conflitos, sendo a mídia a plataforma de confrontos destas.

Embora o status da secularização do campo brasileiro seja diferente do que acontece, por exemplo, na Europa, não se pode negar certo efeito nestes lados de caso. Como já demonstramos anteriormente, a secularização representa o reordenamento do campo das religiões, e que, a partir da fragmentação e dissolução do monopólio da tradição existente, passamos a viver num ambiente de mercado religioso, onde as organizações religiosas passam a disputar um espaço na oferta de seus bens simbólicos. O sociólogo Ricardo Mariano (2002) afirma que neste cenário:

Revista Pax Domini | Faculdade Boas Novas | vol. 1 | p. 102 - 117 | jul./dez. 2015 
O pluralismo religioso tende a acirrar a competição religiosa, uma vez que, para conquistar prosélitos, recursos, poder e reconhecimento social, isto é, para defender seus interesses institucionais em face da concorrência, cada grupo religioso se vê crescentemente compelido a mobilizar seus agentes leigos e eclesiásticos, a exigir deles maior fidelidade, empenho, dedicação, eficiência, dinamismo e militância, a empregar métodos e estratégias do evangelismo mais atraentes e eficazes.

A pluralização só é possível num campo secularizado. E um campo plural é um campo de mercado religioso, e, consequentemente de disputa religiosa. Como afirma Mariano, as organizações religiosas passam agora a lutar por reconhecimento e busca de seus interesses institucionais.

Para Bourdieu (2009, p. 50), esse conflito entre os "especialistas que monopolizam a gestão dos bens de salvação" representa "as relações de concorrência que opõem os diferentes especialistas no interior do campo religioso, constituem o princípio da dinâmica do campo religioso e também das transformações da ideologia religiosa". É um processo próprio a esta estruturação do campo.

A secularização pluraliza o campo religioso o colocando numa lógica de mercado. Nesta lógica de consumo, as religiões são constrangidas a se reorganizarem para atender as novas demandas dos fiéis-clientes. E, na oferta de seus bens de simbólicos, elas entram em disputa e conflito na busca de uma legitimação dentro deste cenário multifacetado.

Parte significativa da dinâmica do campo religioso brasileiro é conduzida pelos conflitos e aproximações, tensões e resistências, estratégias e acomodações geradas pela concorrência da oferta religiosa numa realidade de mercado. Não há grupo religioso que se ausente à pressão e influência desta concorrência. Nesse contexto, as tradições religiosas, quaisquer que elas sejam, são constrangidas pelo ímpeto pragmático de adaptarem seu discurso à comercialização dos bens de salvação. A secularização diversifica a oferta religiosa de dentro de um campo dinamizado pela lógica de mercado gerando um cenário de conflitos e tensões.

Os principais protagonistas destas disputas religiosas são, principalmente, mas não de forma exclusiva, os líderes das instituições religiosas que se colocam no embate direto com as demais igrejas concorrentes. Para Bourdieu (2009, p. 50), esse conflito entre os "especialistas que monopolizam a gestão dos bens de salvação" representa "as relações de concorrência que opõem os diferentes especialistas no interior do campo religioso, constituem o princípio da dinâmica do campo religioso e também das transformações da ideologia religiosa". É um processo próprio a esta estruturação do

Revista Pax Domini | Faculdade Boas Novas | vol. 1 | p. 102 - 117 | jul./dez. 2015 
campo. Com a perda de espaço religioso, as instituições religiosas passa a se valer de estratégias mercadológicas utilizando semântica religiosa na tentativa de resgatar sua legitimidade religiosa. Bourdieu diz:

O tipo de legitimidade religiosa que uma instância religiosa pode invocar depende da posição que ocupa num determinado estado das relações de força religiosas, na medida em que esta posição determina a natureza e a força das armas materiais ou simbólicas que os diferentes agentes em competição pelo monopólio do exercício legítimo da violência religiosa podem utilizar nas relações de força religiosas.

Considerando a posição que determinada instituição religiosa possuía dentro de um campo, e vendo-se ameaçada, utiliza-se de armas simbólicas no exercício do monopólio religioso legítimo. Assim, é intuitivo pensar que com a defasagem e transito religioso dos membros comece a levar a estas instituições religiosas ao uso de um exercício violento de desqualificação de seu oponente religioso. Ainda Bourdieu (2009, p.88):

A concorrência pelo poder religioso deve sua especificidade ao fato de que seu alvo reside no monopólio do exercício legítimo do poder de modificar em bases duradouras e em profundidade a prática e a visão do mundo dos leigos, impondolhes e inculcando-lhes um habitus religioso particular, isto é, uma disposição duradoura, generalizada e transferível de agir e de pensar conforme os princípios de uma visão (quase) sistemática do mundo e da existência.

Essa disputa acontece, entre outros fatores, porque estas instituições oferecem um cosmo sagrados, totalmente estabelecido de referencia e consumo para seus fiéis. Na medida em que essa estrutura "sagrada" é disputada por outro sistema de plausibilidade o conflito se instaura. Neste momento é que surgem as categorias de ortodoxia e heresia para discriminar os polos em conflito. Como Bourdieu afirmou: "uma forma particular da luta pelo monopólio que se instaura quando a Igreja detém um monopólio total dos instrumentos de salvação consiste na oposição entre a ortodoxia e a heresia que se desenvolve segundo um processo mais ou menos constante”.

\section{GLOBALIZAÇÃO E HIBRIDISMO DAS CRENÇAS}

Revista Pax Domini | Faculdade Boas Novas | vol. 1 | p. 102 - 117 | jul./dez. 2015 
Na modernidade religiosa há uma interpenetração entre religião e globalização. Não só as pesquisas apontam essa tendência, como rotineiramente os noticiários demonstram em âmbito local e mundial a religião como força protagonizadora de papeis específico no processo de globalização. Hora contribuindo com movimentos de reforma social na América Latina, hora fomentando a intolerância e a violência religiosa entre grupos religiosos como no Oriente Médio. Dentre os muitos exemplos que podem ser citados como exemplo da religião interferindo e sendo interferida pela política pública, relações econômicas internacionais, ou mídia global, basta nos lembrarmos do vídeo publicado no site Youtube por um produtor californiano que causou tensões entre os cristãos coptas dos EUA e os maometanos no Egito ${ }^{4}$.

Uma das consequências da globalização é diminuição das distâncias entre os modos de vida, política, gostos musicais, inclusive religião. Resultado disto é que os sistemas simbólicos das religiões encontram-se cada vez mais próximos. O anteriormente exótico ou desconhecido torna-se mais próximo dos indivíduos, chegando a compor a rotina básica de sua vida. Não se precisa mais ir necessariamente à Índia para se ter contato com as espiritualidades orientais, basta tão somente recorrer ao grupo de adeptos mais próximos de onde se mora, ou ser telespectador dos diversos programas religiosos transmitidos mundialmente.

O outro não está mais longe, mas agora está bem perto: nas músicas, na decoração de casas (elefantes indianos, pequenos budas, cristais...), companheiros profissionais, colegas de universidade e por ai vai. O consumo dos bens religiosos alheios (músicas, imagens, conceitos, costumes) torna-se possível sem que haja necessariamente o sentimento de transgredir fronteiras. A modernidade religiosa é esta condição sociocultural onde os sistemas simbólicos das diversas e diferentes religiões estão convizinhos e podem se encontrar.

Essa situação provoca certo tipo de hibridização das crenças e práticas religiosas. Estas, antes particulares e exclusivas a um grupo específico passam a se tornar elementos livres para combinações e mesclas por parte dos sujeitos religiosos. Há um tipo de bricolagem dos componentes religiosos em nível de ressignificação, justaposição ou padronização dos gostos, comportamentos e ênfases. Retomando uma análise do campo brasileiro feita por Motta, o sociólogo Jean-Paul Willaime (2012, p.126-128) cita uma referência desse dado da hibridização do religioso:

\footnotetext{
${ }^{4}$ Matéria sobre o caso no sítio: http://www1.folha.uol.com.br/mundo/1152395-hizbollah-diz-que-filme-anti-isla-incita-odioentre-coptas-e-muculmanos.shtml
}

Revista Pax Domini | Faculdade Boas Novas | vol. 1 | p. 102 - 117 | jul./dez. 2015 
O catimbó - culto de cura que se desenvolveu a partir de um núcleo de origem indígena -, o candomblé - a religião afro-brasileira por excelência que incorpora os santos da tradição católica - e a umbanda - corrente que interpreta as religiões afro-brasileiras e indo-brasileiras à luz do espiritismo - são algumas das expressões religiosas que articulam heranças diversas e manifestam a dinâmica evolutiva do religioso capaz de incorporar todos os tipos de contribuições, criando novas formas (...). Encontramos, ali, efetivamente, vários traços do religioso moderno: interpenetração de heranças religiosas diversas e as tendências ao sincretismo, religiões que ajudam a vivenciar o presente, uma apreensão imediata e experimental do sobrenatural, religiões de festa, estruturas nas quais a congregação local ocupa um espaço central. É o momento da mistura, dos sincretismos, dos contatos e interferências múltiplas entre as diversas tradições religiosas, o sincretismo apresentando-se, inclusive, como uma das características mais importantes da cultura moderna atual.

O trecho é bastante elucidativo ao situar de que forma acontecem esses arranjos entre os símbolos e ritos na modernidade religiosa. O campo religioso hoje é aquele onde os limites das confessionalidades se cruzam dando vazão a novas composições religiosas que formam ou não necessariamente grupos novos, ou certo conjunto de práticas corrente.

De forma quase paradoxal em relação a homogeneização dos bens religiosos da oferta global, a modernidade religiosa dialeticamente gera uma tendência fundamentalista as religiões. Estes, vinculados aos regionalismos e nacionalismos surgem como resposta ao chamado "desenraizamento global", pretendendo a preservação das identidades ante um universo religioso fragmentado e indefinível.

Diante de um mercado religioso competitivo e acirrado, como descrito anteriormente, as religiões buscam na consevarção das identidades particulares resguardar os elementos próprios que as distinguem e caracterizam. Essas identidades fundamentalistas costumeiramente tendem a ser tornar exclusivistas e violentas, com pouco ou quase nenhum diálogo com outros grupos religiosos.

Estas realidades desencadeiam uma "flutuação" do religioso. A religião passa a tornar-se uma realidade porosa e fluída que escapa à apreensão de suas manifestações. Muito acertadamente o antropólogo norte-americano Clifford Geertz (2006, p.10) afirmou em entrevista que "a religião se tornou cada vez mais um objeto flutuante, desprovido de ancoragem social em uma tradição fecunda ou

Revista Pax Domini | Faculdade Boas Novas | vol. 1 | p. 102 - 117 | jul./dez. 2015 
em uma instituição estabelecida". A fala de Geertz clareia um importante fenômeno da modernidade religiosa. Na atualidade as diversas tradições religiosas são livres de seus contextos próprios de origem.

As vinculações religiosas antes restritas a espaços geográficos e culturais específicos abrem-se para as adesões por parte de outras localidades do globo. Por exemplo, para ser mulçumano não é preciso viver nos países islâmicos, mas se pode pra ser em qualquer outro país do Ocidente, ou, é possível o desenvolvimento de expressivos grupos de neopentecostais na África, ou do hinduísmo na Inglaterra.

\section{CONSIDERAÇÕES FINAIS}

Ao longo das últimas páginas, tentamos apresentar algumas das dinâmicas religiosas que compõem o quadro das religiões contemporaneamente. Destacamos como a modernidade religiosa leva à um processo de secularização da sociedade, gerando uma religiosidade afeita à marca do individualismo. Também que neste cenário, o religioso entra numa situação de pluralismo e é absorvido pela lógica do mercado na produção e oferta dos bens religiosos. Tal fato, leva as instituições e tradições religiosas a se colocarem em conflitos e tensões na busca de encontrar seu espaço no mercado das religiões. Não apenas isso, mas o fenômeno da globalização gera por um lado, o hibridismo das crenças e, por outro, reações fundamentalistas que tornam a religião cada vez mais um objeto difuso em nossas sociedades.

Diante de tais dados, devemos nos colocar algumas questões: como tais dinâmicas interpelam à produção teológica contemporaneamente? Que desafios estes cenários impõe sobre a teologia evangélica? Que respostas à teologia tem gerado sobre as transformações desencadeadas pela modernidade religiosa? Como particularmente cada uma dessas dinâmicas se colocam como objeção e oportunidade a um labor teológico evangélico? Esperamos ter levantado um primeiro quadro de problemáticas sobre o cenário religioso contemporâneo que deverão ser posteriormente postos como desafio a ser pensados por uma teologia evangélica nacional.

\section{REFERÊNCIAS BIBLIOGRÁFICAS}

BERGER, Peter. O Dossel Sagrado. Elementos para uma Teoria Sociológica da Religião. São Paulo: Paulus, 1985.

Revista Pax Domini | Faculdade Boas Novas | vol. 1 | p. 102 - 117 | jul./dez. 2015 
BOBINEAU, Olivier; TANK-STORPER, Sébastien. Sociologia das religiões. Loyola: São Paulo, 2011.

BOURDIEU, Pierre. A economia das trocas simbólicas. São Paulo: Perspectiva, 2009.

GUERRA, Lemuel. As influências da lógica mercadológica sobre as recentes transformações na igreja católica. Revista de Estudos da Religião. n.2, 2003, p.1-23.

HERVIEU-LÉGER, Danièle. O peregrino e o convertido: a religião em movimento. Petrópolis: Vozes, 2008a.

LENOIR, Frédéric. Les metamorphoses de Dieu : la nouvelle spiritualité occidentale. Paris : Plon, 2003.

MARIANO, Ricardo. Secularização do Estado, liberdades e pluralismo religioso. Ciudad Virtual de Antropologia $\quad \mathbf{y}$ Arqueologia, 2003. Disponível em: <www.naya.org.ar/congresso2002/ponencias/ricardo_mariano>. Acesso em 25/06/2012.

MOREIRA, Alberto da Silva. O futuro da religião no mundo globalizado: painel de um debate. In: MOREIRA, Alberto da Silva; OLIVEIRA, Irene Dias (org.). O futuro da religião na sociedade global: uma perspectiva multicultural. São Paulo: Paulinas, 2008..

PORTELLA, Rodrigo. A religião na sociedade secularizada: urdindo as tramas de um debate. NUMEN, Juiz de Fora, v.11, n 1 e 2, 2006, p.33-53.

PRANDI, Reginaldo. Religião, biografia e conversão: escolhas religiosas e mudanças da religião. Rio de Janeiro, 1999. Mimeo.

RIVERA, Paulo Barrera. Fragmentação do sagrado e crise das tradições na pós-modernidade. In: TRASFERETTI, José (Org.). Teologia na pós-modernidade. São Paulo: Paulinas, 2003. p. 437-464.

SANCHES, Wagner Lopes. Pluralismo religioso: as religiões no mundo atual. São Paulo: Paulinas, 2005.

SANCHIS, Pierre. Pluralismo, transformação, emergência dos indivíduos e suas escolhas. IHU OnLine, São Leopoldo, RS, Edição 400, ago./2012, p. 5-7. Disponível em http://www.ihuonline.unisinos.br/index.php?secao=400.

WILLAIME, Jean-Paul. Sociologia das religiões. São Paulo: Editora Unesp, 2012.

Revista Pax Domini | Faculdade Boas Novas | vol. 1 | p. 102 - 117 | jul./dez. 2015 